\title{
Electrocatalytic oxidation of methanol on CoNi electrodeposited materials
}

X. Tarrús, M. Montiel*, E. Vallés, E. Gómez

Departament de Química Física and Institut de Nanociència i Nanotecnologia (IN $\left.{ }^{2} \mathrm{UB}\right)$, Universitat de Barcelona, Martí i Franquès 1, E-08028 Barcelona, Spain.

*Author to whom correspondence should be addressed

e-mail: manuel.montiel@ub.edu

Phone: +34 934039241

Fax: +34 934021231 


\begin{abstract}
Cobalt-nickel bimetallic materials electrodeposited on $\mathrm{Si} / \mathrm{Ti} / \mathrm{Ni}$ substrates were evaluated for the oxidation of methanol in alkaline media. CoNi samples were prepared potentiostatically selecting the adequate conditions to achieve the desired $\mathrm{Co} / \mathrm{Ni}$ ratio. All samples were characterized by X-ray fluorescence and cyclic voltammetry to determine their composition and electrochemical behavior. The electrocatalytical performance of prepared samples was evaluated also by cyclic voltammetry using methanol solutions in alkaline media. Material composition, methanol and $\mathrm{NaOH}$ concentration, and temperature were the variables studied. The results indicate that excessive amount of cobalt inhibits the methanol oxidation reaction. In the same way, significant enhancement of the oxidation current is observed increasing the $\mathrm{NaOH}$ concentration up to $0.5 \mathrm{M}$, but from this value the electrocatalytic performance of these materials decreases. With regard to the increase of $\mathrm{MeOH}$ concentration or temperature, both variables are related to an improvement of the electrocatalytic performance. Finally, the effect of platinum skin on the CoNi deposits was evaluated, concluding that it favours $\mathrm{MeOH}$ oxidation but does not protect from the damage exerted by excessive $\mathrm{NaOH}$ concentration over the substrate surface.
\end{abstract}

\title{
Keywords
}

Methanol; electrocatalytic oxidation; alkaline medium; electrodeposition; CoNi alloys; cyclic voltammetry studies

\section{Introduction}

In recent years, direct methanol fuel cells (DMFC) have gained interest as possible power devices, especially for portable electronic devices and electric vehicles. Among different possible alcohols, methanol is one of the most promising fuels because holds the advantages of high energy density, low operating temperatures, usage in aqueous electrolytes, low cost and easy fuel delivery and storage [1-6]. Methanol is usually produced using the synthesis gas route $\left(\mathrm{CO}+\mathrm{H}_{2}\right)$ from fossil reserves such as natural gas or coal. Along with it, synthesis gas and therefore methanol can be produced in large quantities from biomass, maintaining unchanged the balance of carbon dioxide in the atmosphere [7-9]. 
Platinum group metals and alloys are the most effective electrocatalysts for the methanol oxidation in acid media, but they have two important disadvantages besides the high cost of metals: kinetic constraints and catalyst poisoning by CO $[10,11]$. Nevertheless in an alkaline electrolyte, the kinetics would significantly improve as compared with the acid counterpart. But, the issue of the cost of the electrocatalytic material deserves be resolved. Alkaline medium, additionally, allows the use of platinum free electrocatalysts, eliminating the problem of the catalysts poisoning by CO. So, a great deal of interest has been focused on the search of alternative transition materials cheaper than platinum.

Nickel is considered as a suitable electrocatalyst for the conversion of small organic molecules in basic media, due to its surface oxidation properties connected with the proposed formation of nickel hydroxides [12-15], that along with its relatively low cost and abundance in nature make it and its alloys some of the best candidates as electrocatalysts in the DMFC. Likewise, parallel studies have been found that the presence of certain metal cations such as cobalt, zinc or cadmium can affect the electrocatalytical behavior of nickel. Addition of $\mathrm{Co}(\mathrm{OH})_{2}$ to nickel electrodes may increase the oxygen evolution potential and the charge acceptance of Ni electrodes [16-21].

In the present work CoNi deposits have been tested as a less-expensive way to allow effective methanol electrocatalyst. CoNi alloy is a versatile material used in many applications due to its wide range of properties. CoNi electrochemical preparation is well established [22-25]. It allows obtaining different composition ratios with little efforts. As well, the possible enhancing of the electrocatalytic performance of CoNi modified by skin Pt surface was investigated. Platinum skin was obtained by means galvanic displacement reaction. Studies about the possibilities of the prepared CoNi materials as electrocatalyst have been performed mainly by cyclic voltammetry.

\section{Experimental}

A conventional three-electrode cell and a potentiostat/galvanostat Autolab with GPES software were used. Preparation of CoNi deposits was performed from solutions freshly prepared, containing $\mathrm{NiCl}_{2}, \mathrm{CoCl}_{2}, \mathrm{H}_{3} \mathrm{BO}_{3}$ and saccharin at $\mathrm{pH}=3$ and $\mathrm{T}=55^{\circ} \mathrm{C}$. The $\mathrm{pH}$ of the solutions was carefully controlled in order to minimize the hydrogen reaction evolution during the preparation. The $\mathrm{pH}$ was measured before and after operating CoNi plating, and 
did not deviate from the initial value. The $\mathrm{Ni}(\mathrm{II}) / \mathrm{Co}(\mathrm{II})$ ratio in solution was varied between 10 and 5.

The reference electrode was $\mathrm{Ag} / \mathrm{AgCl}$ mounted in a Luggin capillary containing $3 \mathrm{M} \mathrm{KCl}$. The counter electrode was a platinum spiral. Vitreous carbon was the selected working electrode to establish the adequate electrodeposition conditions. Previous to each experiment the substrate was polished using alumina $(1.75$ and $3.75 \mu \mathrm{m})$ conveniently rinsed for 2 minutes in Millipore Milli Q water in an ultrasonic bath. Deposits were prepared on test samples of $\mathrm{Si} / \mathrm{Ti}(100 \mathrm{~nm}) / \mathrm{Ni}(50 \mathrm{~nm})$. The Ti/Ni seed layer was obtained by sputtering, and supply the good electrical connection required by the electrochemical experiments.

The deposits composition was evaluated using X-Ray Fluorescence (XRF) (Fisherscope XRay DAL) and EDX analysis of JEOL JSM-840. X-Ray diffraction (XRD) phase analysis was performed on a PAnanalytical X'Pert-PRO MRD diffractometer. The $\mathrm{Cu} \mathrm{K} \alpha$ radiation $(\lambda=0.15418 \mathrm{~nm})$ was selected by a means of a diffracted beam flat graphite crystal. $2 \theta / \theta$ diffractograms were obtained in the $5-120^{\circ} 2 \theta$ range with a step of $0.035^{\circ}$ and a measuring time of 5 s per step. X-ray photoelectron spectroscopy (XPS) measurements of the binding energies (BE) were performed with a PHI 5600 multitechnique system.

Electrochemical study focused on methanol oxidation was made using a conventional cell of three electrodes, using $\mathrm{NaOH}$ and $\mathrm{MeOH}$ solutions from reactants of analytical grade, the same counter and reference electrodes than under preparation experiments and as working electrodes the different CoNi samples prepared.

\section{Results}

\subsection{Electrochemical preparation of substrata}

The preparation of the CoNi coatings was performed at from $\mathrm{NiCl}_{2} 1 \mathrm{M}+\mathrm{CoCl}_{2} x \mathrm{M}+\mathrm{H}_{3} \mathrm{BO}_{3}$ $0.5 \mathrm{M}+$ saccharin $3.810^{-3} \mathrm{M}$ solutions varying $x$ between 0.1 and 0.2 . A previous voltammetric study was made using vitreous carbon as substrate in order to establish the electrochemical behaviour and the potential range at which CoNi deposition takes place (Figure 1A, curve a). Scanning at first to negative values, typical features for a nucleation and growth process were recorded after reversing the scan, followed by an oxidation peak during the positive scan, corresponding to the alloy oxidation [25,26]. Similar voltammetric 
behaviour was obtained using $\mathrm{Si} / \mathrm{Ti} / \mathrm{Ni}$ as working electrode, although the reduction current appearance occurs before (Figure 1A, curves b and c).

Selected the potential range, potentiostatic study revealed that at first the $\mathrm{j}$-t transients show progressive increase in current with time, which evolves into a steady value, greater as more negative was the applied potential (Figure 1B). The compositional characterization of the prepared samples makes in evidence that anomalous deposition occurs [27]. Decreasing applied potential, the nickel percentage increases to attain a quasi steady value, as the manner that to increment cobalt percentage it was necessary to decrease $\mathrm{Ni}(\mathrm{II}) / \mathrm{Co}$ (II) in solution (Table 1). Gentle stirring of the solution prevents composition variation thorough the deposit thickness and favours the cobalt incorporation in the deposit. For all applied potentials, deposits were smooth and fine grained (Figure 2A), although those prepared at the more negative potentials show some holes due to hydrogen codeposition. The structural characterization of these deposits confirms fcc-CoNi solid solution formation accompanied by low presence of hydroxides for the deposits obtained at the lowest potentials. As deposits are nickel-rich, the diffraction peaks of the alloy were near the position of the pure fcc-Ni peaks (Figure 2B).

Considering these results, deposits were prepared potentiostatically under gentle agitation selecting the bath solution according to the CoNi percentage desired (75, 60 and $50 \mathrm{Ni}$ wt. \%) at potentials at which interference of hydrogen coevolution was minimized. The solution with $0.2 \mathrm{M}$ of $\mathrm{Co}(\mathrm{II})$ was chosen in the preparation of the Co richer deposits, because allowed less negative applied potentials.

It is worth noting that this study has been carried out using $\mathrm{Si} / \mathrm{Ti} / \mathrm{Ni}$ test samples as support for CoNi catalyst. Employment of this substratum is owing to the ease to perform the measurement in half-cell. This electrodeposition method can be used to prepare samples over other conductive supports as metals, glassy carbon, or porous carbon.

\subsection{Electrochemical behaviour of the $\mathrm{CoNi}$ coatings in $\mathrm{NaOH}$ solutions}

Previous to study the methanol oxidation in alkaline medium, it was considered to analyze the electrochemical response of a 75 wt. \% Ni substrate in the blank solution. At first, it was selected a $0.1 \mathrm{M} \mathrm{NaOH}$ solution. Voltammetric curves were recorded by cycling the potential between 0.1 and $0.65 \mathrm{~V}$ at $20 \mathrm{mV} \mathrm{s}^{-1}$. During the positive scan, prior to oxygen evolution a wide oxidation peak appeared which maximum was located around $0.47 \mathrm{~V}$ (Figure 3A). This peak is related to the $\mathrm{Ni}(\mathrm{OH})_{2} / \mathrm{NiOOH}$ oxidation process [28]. Likewise, in the negative scan 
the corresponding reduction peak was centred around $0.39 \mathrm{~V}$. Consecutive scans gave an increase of the involved charge, as the manner that the voltammogram attains steady profile and subsequent curves are reproducible. Increasing the $\mathrm{NaOH}$ concentration similar electrochemical behaviours were observed, although a shift to lower potential values of the oxidation peak occurs.

\subsection{Methanol oxidation on CoNi}

Adding methanol to the $0.1 \mathrm{M} \mathrm{NaOH}$ solution just attain $0.1 \mathrm{M} \mathrm{MeOH}$, voltammograms were recorded at $20 \mathrm{mV} \mathrm{s}^{-1}$ using CoNi 75 wt. \% as electrode. In the positive sweep beyond the oxide formation, a new current feature associated to methanol oxidation was recorded previous to oxygen evolution (Figure 3B). In the backward scan, also positive current was observed previous to the oxide reduction. As the interest of these materials is the continuous work, the effect of consecutive cycles on the voltammetric response was considered. The electrode was cycled consecutively for 60 cycles. As previously observed in the blank solution, current slightly increased with cycling, up to a constant value get at cycle 30, number of cycles from now will consider in order comparison of results.

Voltammetric experiments using substrata of the compositions prepared, (50, $60 \mathrm{wt}$ \% Ni) show similar profiles that those obtained using CoNi substratum of $75 \mathrm{wt}$. \% Ni, revealing that independently of the cobalt percentage in the alloy, all tested CoNi compositions result electrocatalytic to methanol oxidation. However, as the cobalt content in the deposit increases the recorded methanol oxidation current diminishes and their appearance delayed slightly to more positive potentials (Figure 3B). According to this result, it was decided pursue the characterization study of the materials in the methanol oxidation reaction using exclusively CoNi with 75 wt. \% Ni as substrate.

Prior the analysis of the influence of different parameters over the recorded methanol oxidation current, it was considered to test the influence of activation step involving previous cycling of the electrode in the alkaline solution. The selected protocol consisted in applying continuous voltammetric scans at $50 \mathrm{mV} \mathrm{s}^{-1}$ between 0.1 and $0.65 \mathrm{~V}$ just during 40 cycles in the blank solution [16]. The observed behaviour of the electrode was similar to the previous one analysed at lower scan rate, and the current progressively increases just to reach a maximum. Afterwards, the electrode was immersed in the methanol solution. The consecutive voltammograms recorded show that increasing the cycle number continuous decrease in the 
current associated to methanol oxidation just attains a stationary value, whereas the associated to the charge/discharge of electrode remains constant independently of the cycle number.

The comparison at fixed conditions of the voltammograms recorded using electrodes with and without previous activation evidenced that, in the first sweeps at equal number of scans, the recorded current was greater using activated electrode. But, increasing the cycle number, the difference between currents narrows. Although the stationary current value attained with activation it is always slightly higher, it was considered that this difference was not significant to justify the time consuming in the activation process.

The influence on the overall process of both reactants was also considered. At first the influence of the alkaline medium maintaining $\mathrm{MeOH}$ concentration at $0.1 \mathrm{M}$ was analysed. The $\mathrm{NaOH}$ concentration was progressively increased in the solution in order to evaluate the effect of the hydroxyl concentration on methanol oxidation current. For all $\mathrm{NaOH}$ concentrations studied, the general profile of voltammetric curves was similar, but an advancement of the processes, both charge/discharge electrode and methanol oxidation was observed increasing $\mathrm{NaOH}$ concentration. The comparison of the voltammetric current recorded after stabilization evidences that, the increase of $\mathrm{NaOH}$ concentration up to $0.5 \mathrm{M}$ gave a significant enhancement of the oxidation current recorded, but from this value, the $\mathrm{NaOH}$ concentration increase in solution causes a clear diminution of current related to methanol oxidation (Figure 4). The current recorded at $1 \mathrm{M} \mathrm{NaOH}$ was smaller than that recorded at $0.1 \mathrm{M}$. It appears that the chemical hydroxylated species presumably formed on the substrate at the highest $\mathrm{NaOH}$ concentrations perturb the surface, as the manner that the species formed lose part of their catalytic activity.

In the same way, the influence of $\mathrm{MeOH}$ concentration was investigated. The progressive increase of $\mathrm{MeOH}$ concentration in the solution leads to a subsequent increase of the recorded current, although the relative increase was softened with the increase of methanol content in the solution. Similar behaviour was observed independently of $\mathrm{NaOH}$ concentration in solution, although, evidently, the recorded currents depend of the $\mathrm{NaOH}$ concentration. Figure 5 collects the stationary currents recorded at different $\mathrm{NaOH}$ concentrations, and makes in evidence the prevalence of $0.5 \mathrm{M}$, condition at which the greater currents were obtained for all $\mathrm{MeOH}$ concentrations analysed. It is noteworthy that the increase of $\mathrm{MeOH}$ concentration does not carry significant advancement of the oxidation process in none of the $\mathrm{NaOH}$ concentrations studied.

Established that the best conditions correspond to the $0.5 \mathrm{M} \mathrm{NaOH}$ solution, was also considered the voltammetric analysis of the temperature influence on the methanol oxidation 
reaction at these conditions. The selected solution was that containing $0.1 \mathrm{M} \mathrm{MeOH}$. An increase of the recorded current associated to methanol oxidation was observed as the temperature rose (Figure 6), accompanied by an important advancement of the oxygen evolution reaction. Similar results were obtained both rising and descending temperature. As a manner of test, experiments from $0.1 \mathrm{M} \mathrm{NaOH}$ solution were performed, the general behaviour was similar to the observed at the $0.5 \mathrm{M} \mathrm{NaOH}$ solution, it is to say, clear increase of current recorded rising temperature, although at these conditions, the effect on the oxygen evolution was moderate.

As the final application of this kind of substrata supposes the continuous use of the material during a long term process, potentiostatic experiments were performed applying potential values corresponding to methanol oxidation. In all conditions the $\mathrm{j}$-t recorded shows a sharp current diminution followed by a smooth one, just to attain a stationary value (Figure 7). Stirring the solution during the experiment, the profile is compatible with the former description although the stabilization was achieved at shorter times. In order to analyze the process related to current diminution, the effect of pulsed signal was investigated. A double step signal was used. The system was carried out alternatively between potentials at which methanol oxidation occurs followed to that at which alcohol oxidation does not occur. Two pairs of potential values were selected. Methanol oxidation potential $\left(E_{1}\right)$ was always selected corresponding to the potential range at which quasi stationary voltammetric oxidation current was observed. In the first pulsed signal investigated, the second potential $\left(E_{2}\right)$ was selected in the potential range at which substratum oxidation occurs. At these conditions the successive potential steps recorded (Figure $7 \mathrm{~B}$ ) show that during the application of $\mathrm{E}_{1}$ a sharp current increase occurs followed by a continuous decrease of current during the pulse length. At $E_{2}$, the current drops to very low positive values. The comparison of the consecutive curves show that the current value recorded at the end of $\mathrm{E}_{1}$ diminishes as the number of cycles increases. In the second pulsed signal the $\mathrm{E}_{2}$ potential corresponds to a potential value previous to the electrode oxidation. Using this kind of values for $E_{2}$, the recorded current at the end of the pulse length in $\mathrm{E}_{1}$ was greater as the cycle number increases (Figure 7C). At these conditions, the influence of the length of the pulse in $E_{2}$ was investigated maintaining the length of pulse in $E_{1}$ at $150 \mathrm{~s}$. Experiments were performed at different $t_{2}$ values. It was observed that it was necessary pulse lengths $\left(\mathrm{t}_{2}\right)$ greater than $10 \mathrm{~s}$ to improve the recorded current for the methanol oxidation as the number of steps increases, using $t_{2}=10 \mathrm{~s}$ it was only achieved to keep the current. 
These results could be interpreted in line of a poisoning of the electrode during the methanol oxidation, so that a certain potential value must be attained in order to achieve the reduction of poison species, being the "cleaning" a relatively slow process.

\subsection{Methanol oxidation on CoNiPt. Skin Pt on CoNi deposits}

Known the general behaviour of the methanol oxidation on the prepared CoNi deposits, the substrate modification with Pt was proposed in order to evaluate the capability of the modified material and the effect of the surface Pt presence on the CoNi in the methanol oxidation. Partial platinum skin was incorporated to the substrate by means a displacement reaction, immersing the CoNi substratum in a solution containing $0.4 \mathrm{mM}$ of $\mathrm{Pt}(\mathrm{IV})$. This concentration was selected because allows to modify the surface Pt amount varying the immersion duration, in affordable times. The effectiveness of the reduction process was

previously tested using long immersion times in which was detected important Pt presence even using these low Pt(IV) concentration.

The interest was focused on the effect of the partial Pt skin presence on the CoNi deposits. Substrata with 75 wt. Ni \% were subjected to different immersion times to vary the Pt content on the substratum. The recorded voltammograms show similar features that to those observed using Pt-free CoNi substrata. The comparison between the voltammetric response obtained from Pt-free CoNi and CoNiPt substrata evidences that the Pt presence enhances the current related to methanol oxidation. However, upon increasing the immersion time the relative current change was moderated (Figure 8).

Established that the Pt presence exerts favourable effect, it was noted that, as occurs using Ptfree $\mathrm{CoNi}$, the increase of $\mathrm{NaOH}$ concentration advances and favours also the oxidation processes, but the enhancing of methanol oxidation current occurs until the $\mathrm{NaOH}$ concentration rose to $0.5 \mathrm{M}$, concentration from which the recorded current begins to decrease, as occurs over the Pt-free CoNi substrata. The Pt presence is unable to overcome the damage effect that the excessive $\mathrm{OH}^{-}$concentration exerts over the substrate surface.

\subsection{XPS characterization of substrata before and after methanol oxidation}

XPS characterization was performed in order to confirm the state of the elements present in both freshly prepared deposits and on the surface after having service as electrocatalyst for methanol. At first, a superficial analysis of freshly prepared samples was performed before 
and after surface cleaning with argon ions during short time in order to remove physiadsorbed carbon and superficial oxygen. The corresponding spectra in the $2 \mathrm{p}$ spectra region of both components confirm the metallic nature of the alloy prepared. The features corresponding to both nickel and cobalt in metallic state appear, with the main peaks centered at $852.8 \mathrm{eV}$ for nickel and at $778.2 \mathrm{eV}$ for cobalt respectively (Figure 9A and B). These results are coincident with those obtained after consecutive runs, confirming that the CoNi coating prepared maintain composition and nature throughout the deposit.

XPS analysis will attempt to elucidate also the superficial oxidation state of the deposits after experimental voltammetric cycling in different alkaline media. The selected samples were two CoNi substrata with nickel percentage of 75 wt. \% that had been previously cycled in $\mathrm{NaOH}$ 0.5 or $0.7 \mathrm{M}$ solutions containing $\mathrm{MeOH}$. Significant changes were observed in the spectra respect to those recorded in the freshly prepared sample. In the nickel energy range, a wide peak was recorded centred at $856 \mathrm{eV}$ (Figure 9C, curves a and b), as corresponds to the presence of oxide/hydroxides of $\mathrm{Ni}(\mathrm{III})$. In the energy range of cobalt, a band peak between 779.5 and $780.2 \mathrm{eV}$ was recorded (Figure 9D, curves a and b), related to the possible existence of $\mathrm{Co}_{3} \mathrm{O}_{4}, \mathrm{Co}_{2} \mathrm{O}_{3}$ or/and $\mathrm{CoOOH}$. Although these results are not conclusive about the species present on the surface, confirm the existence of oxides or hydroxylated forms of both Ni (III) and Co (III) formed during the voltammetric cycling. The XPS analysis of these samples after sputtering with argon ions during certain time was also performed to analyze the composition in depth, after removing the formed superficial layer, the XPS spectra (Figures 9C and 9D, curves c) were similar to those obtained from the freshly prepared samples, demonstrating that the formation of oxide/hydroxilated species in the work conditions corresponds to a superficial process.

\section{Conclusions}

CoNi electrodeposited materials have been tested as catalysts for electrochemical oxidation of methanol in alkaline solution and their electrocatalytical performance and optimal working conditions are showed. Structural characterization of these materials confirms that they are deposited as a CoNi solid solution with low presence of hydroxylated species. Electrocatalytic measurements by cyclic voltammetry indicated that excessive amount of cobalt in the samples (above 25 wt. \%) inhibits the methanol oxidation. In the same way, concentration of $\mathrm{NaOH}$ greater than $0.5 \mathrm{M}$ perturbs the surface of material and the catalyst performance decreases. The progressive increase of $\mathrm{MeOH}$ concentration in the solutions revealed in all cases an 
increase of the recorded current up to a quasi-stationary value. Also, the beneficial effect of the temperature increase has been demonstrated. The presence of a partial Pt-skin favours $\mathrm{MeOH}$ oxidation but is unable to overcome the damage that the excessive $\mathrm{OH}^{-}$concentration exerts over the substrate surface.

All results reported in this work indicate the performance of the Ni-rich CoNi coating as good candidate to be implemented as electrocatalyst in the DMFC. This will require CoNi deposit on porous carbon structures increasing both the available surface and accessible passage of fuel. The general ease CoNi electrodeposition on different substrates opens the possibility to obtain these CoNi deposits on the required substrata without much effort obtaining significant economical savings.

\section{Acknowledgements}

Financial support from the MINECO contract CTQ2010-20726 (subprogram BQU) is grateful acknowledged. The authors wish to thank the Centres Científics i Tecnològics de la Universitat de Barcelona (CCiTUB) for the use of their equipment and the Instituto de Microelectrónica de Barcelona del Centro Nacional de Microelectrónica (CNM-CSIC) for the $\mathrm{Si} / \mathrm{Ti} / \mathrm{Ni}$ test samples supply. M. Montiel acknowledges the Generalitat de Catalunya for support in the form of a Beatriu de Pinós postdoctoral fellowship.

\section{Figure Captions}

Figure 1. From 1.0 M Ni(II) and 0.1 M Co(II) solution: A) Cyclic voltammograms on: a) vitreous carbon, b) $\mathrm{Si} / \mathrm{Ti} / \mathrm{Ni}$, and c) $\mathrm{Si} / \mathrm{Ti} / \mathrm{Ni}$ at $\omega=100$ r.p.m. Scan rate $50 \mathrm{mV} \mathrm{s}^{-1}$. B) j-t transients at a) $-800 \mathrm{mV}$, b) -850 and c) $-880 \mathrm{mV}$.

Figure 2. A) SEM image of CoNi deposit obtained from $1.0 \mathrm{M} \mathrm{Ni(II)} \mathrm{and} 0.1 \mathrm{M} \mathrm{Co}(\mathrm{II})$ solution at $-880 \mathrm{mV}, \mathrm{B}$ ) corresponding XRD pattern.

Figure 3. Cyclic voltammograms from: A) $0.1 \mathrm{M} \mathrm{NaOH}$ solution after 10, 20, 30 and 40 consecutive cycles. B) $0.1 \mathrm{M} \mathrm{NaOH}+0.1 \mathrm{MeOH}$ solution from different CoNi percentages: a) $75 \mathrm{wt}$. \%, b) $60 \mathrm{wt}$. \%, and c) $50 \mathrm{wt}$. \%. Scan rate $20 \mathrm{mV} \mathrm{s}^{-1}$ and cycle $\mathrm{n}=30$. 
Figure 4. A) Cyclic voltammograms from $x \mathrm{M} \mathrm{NaOH}+0.1 \mathrm{MeOH}$ solutions: $x=0.1, x=0.5$, $x=0.7$, and $x=1$. Scan rate $20 \mathrm{mV} \mathrm{s}^{-1}$ and cycle $\mathrm{n}=30$. B) Dependence of the voltammetric methanol oxidation current with the $\mathrm{NaOH}$ concentration.

Figure 5. Dependence of the voltammetric methanol oxidation current with the $\mathrm{MeOH}$ concentrations at different $\mathrm{NaOH}$ concentrations: $0.1 \mathrm{M}, 0.5 \mathrm{M}, 0.7 \mathrm{M}$ and $1 \mathrm{M}$. Cycle 30 and scan rate $20 \mathrm{mV} \mathrm{s}^{-1}$.

Figure 6. Dependence of the voltammetric methanol oxidation current with temperature from $0.5 \mathrm{M} \mathrm{NaOH}+0.1 \mathrm{MeOH}$ solution, cycle 30 and scan rate $20 \mathrm{mV} \mathrm{s}^{-1}$.

Figure 7. Chronoamperograms from CoNi electrode in the $0.5 \mathrm{M} \mathrm{NaOH} 0.1 \mathrm{M} \mathrm{MeOH}$ solution: A) at constant oxidation potential $\mathrm{E}_{1}=0.58 \mathrm{~V}$, and using pulsed signal $\left.\mathrm{B}\right) \mathrm{E}_{1}=0.58 \mathrm{~V}$ and $E_{2}=0.35 \mathrm{~V}$ and $\left.\mathrm{C}\right) \mathrm{E}_{1}=0.58 \mathrm{~V}$ and $\mathrm{E}_{2}=0.1 \mathrm{~V}$ using pulse lengths of $\mathrm{t}_{1}=150 \mathrm{~s}$ and $\mathrm{t}_{2}=50 \mathrm{~s}$.

Figure 8. Cyclic voltammograms from $0.1 \mathrm{M} \mathrm{NaOH}+0.1 \mathrm{MeOH}$ solutions from CoNi electrodes after immersion in a $0.4 \mathrm{mM}$ solution of sodium hexachloroplatinate (IV) during: 0 s, $30 \mathrm{~s}, 60 \mathrm{~s}$ and $90 \mathrm{~s}$.

Figure 9. XPS spectra recorded for CoNi depostit freshly prepared: A) Ni 2p and B) Co 2p, and CoNi deposit after service in $0.5 \mathrm{M} \mathrm{NaOH} \mathrm{0.1} \mathrm{M} \mathrm{MeOH}$ solution: C) Ni 2p3 and D) Co 2p. Curves a, b, and c correspond to consecutive runs with argon.

\section{References}

[1] Shih Z-Y, Yang Z, Lin Z-H, Chang H-T. Direct methanol fuel cells using Se/Ru core/shell cathodes provide high catalytic activity and stability. International Journal of Hydrogen Energy 2011;36:7303-9.

[2] Jha N, Jafri RI, Rajalakshmi N, Ramaprabhu S. Graphene-multi walled carbon nanotube hybrid electrocatalyst support material for direct methanol fuel cell. International Journal of Hydrogen Energy 2011;36:7284-90. 
[3] Ahmadi R, Amini MK. Synthesis and characterization of Pt nanoparticles on sulfurmodified carbon nanotubes for methanol oxidation. International Journal of Hydrogen Energy 2011;36:7275-83.

[4] Wang L, Tian C, Wang H, Ma Y, Wang B, Fu H. Mass Production of Graphene via an in Situ Self-Generating Template Route and Its Promoted Activity as Electrocatalytic Support for Methanol Electroxidization. Journal of Physical Chemistry C 2010;114:8727-33.

[5] Yuan D, Tan S, Liu Y, Zeng J, Hu F, Wang X, et al. Pt supported on highly graphitized lace-like carbon for methanol electrooxidation. Carbon 2008;46:531-6.

[6] Lamy C, Lima A, LeRhun V, Delime F, Coutanceau C, Léger J-M. Recent advances in the development of direct alcohol fuel cells (DAFC). Journal of Power Sources 2002;105:283-96.

[7] Cherubini F. The biorefinery concept: Using biomass instead of oil for producing energy and chemicals. Energy Conversion and Management 2010;51:1412-21.

[8] Kempegowda RS, Pannir Selvam PV, Skreiberg Ø, Tran K-Q. Process synthesis and economics of combined biomethanol and CHP energy production derived from biomass wastes. Journal of Chemical Technology \& Biotechnology 2012;87:897-902.

[9] Balegedde Ramachandran RP, Oudenhoven SRG, Kersten SR a., van Rossum G, van der Ham a. GJ. Techno-Economic Analysis of Biomethanol Production via Hybrid Steam Reforming of Glycerol with Natural Gas. Energy \& Fuels 2013;27:5962-74.

[10] Hernández-Fernández P, Montiel M, Ocón P, García-Fierro JL, Wang H, Abruña HD, et al. Effect of Co in the efficiency of the methanol electrooxidation reaction on carbon supported Pt. Journal of Power Sources 2010;195:7959-67.

[11] Montiel M, Hernández-Fernández P, García-Fierro JL, Rojas S, Ocón P. Promotional effect of upper Ru oxides as methanol tolerant electrocatalyst for the oxygen reduction reaction. Journal of Power Sources 2009;191:280-8.

[12] Golikand AN, Asgari M, Maragheh MG, Shahrokhian S. Methanol electrooxidation on a nickel electrode modified by nickel-dimethylglyoxime complex formed by electrochemical synthesis. Journal of Electroanalytical Chemistry 2006;588:155-60.

[13] Skowroński JM, Ważny A. Nickel Foam-based $\mathrm{Ni}(\mathrm{OH}) 2$ /NiOOH Electrode as Catalytic System for Methanol Oxidation in Alkaline Solution. Journal of New Materials for Electrochemical Systems 2006;9:345-51. 
[14] Nagashree KL, Ahmed MF. Electrocatalytic oxidation of methanol on Ni modified polyaniline electrode in alkaline medium. Journal of Solid State Electrochemistry 2010;14:2307-20.

[15] Fleischmann M, Korinek K, Pletcher D. The oxidation of organic compounds at a nickel anode in alkaline solution. Journal of Electroanalytical Chemistry and Interfacial Electrochemistry 1971;31:39-49.

[16] Asgari M, Maragheh MG, Davarkhah R, Lohrasbi E, Golikand AN. Electrocatalytic oxidation of methanol on the nickel-cobalt modified glassy carbon electrode in alkaline medium. Electrochimica Acta 2012;59:284-9.

[17] Oshitani M, Takayama T, Takashima K, Tsuji S. A study on the swelling of a sintered nickel hydroxide electrode. Journal of Applied Electrochemistry 1986;16:403-12.

[18] Oshitani M, Sasaki Y, Takashima K. Development of a nickel electrode having stable performance at various charge and discharge rates over a wide temperature range. Journal of Power Sources 1984;12:219-31.

[19] Cox P, Pletcher D. Electrosynthesis at oxide coated electrodes Part 1 the kinetics of ethanol oxidation at spinel electrodes in aqueous base. Journal of Applied Electrochemistry 1990;20:549-54.

[20] Telli E, Döner A, Kardaş G. Electrocatalytic oxidation of methanol on Ru deposited NiZn catalyst at graphite in alkaline medium. Electrochimica Acta 2013;107:216-24.

[21] Altunbaş Şahin E, Kardaş G. Cobalt-modified nickel-zinc catalyst for electrooxidation of methanol in alkaline medium. Journal of Solid State Electrochemistry 2013;17:2871-7.

[22] Chung CK, Zhou RX, Chang WT. The anomalous behavior and properties of Ni-Co films codeposited in the sulfamate-chloride electrolyte. Microsystem Technologies 2008;14:1279-84.

[23] Correia A., Machado SA. Electrodeposition and characterisation of thin layers of NiCo alloys obtained from dilute chloride baths. Electrochimica Acta 2000;45:1733-40.

[24] Goldbach S, Kermadec R De, Lapicque F. Electrodeposition of Ni \pm Co alloys from sulfamate baths. Journal of Applied Electrochemistry 2000;30:277-84.

[25] Gómez E, Ramírez J, Vallés E. Electrodeposition of Co-Ni alloys. Journal of Applied Electrochemistry 1998;28:71-9.

[26] Gómez E, Vallés E. Electrodeposition of Co+Ni alloys on modified silicon substrates. Journal of Applied Electrochemistry 1999;29:805-12. 
[27] Brenner A. Electrodeposition of alloys: principles and practice, Volume II. New York: Academic Press; 1963.

[28] Norouzi B, Norouzi M. Methanol electrooxidation on novel modified carbon paste electrodes with supported poly(isonicotinic acid) (sodium dodecyl sulfate)/Ni-Co electrocatalysts. Journal of Solid State Electrochemistry 2012;16:3003-10. 
Table 1. Composition of CoNi samples and experimental conditions

\begin{tabular}{ccccc} 
Solution & -E (V) & \multicolumn{3}{c}{ Ni (wt. \%) } \\
\cline { 3 - 5 } & & $\mathbf{0 ~ r p m}$ & $\mathbf{1 0 0} \mathbf{~ p m}$ & $\mathbf{3 0 0} \mathbf{~ r p m}$ \\
\hline 1M Ni(II) + 0.1M Co(II) & 0.75 & & 59 & \\
& $0.80^{\mathrm{b}}$ & 70 & 62 & \\
& 0.85 & 72 & 63 & \\
& 0.90 & 75 & & 61 \\
& 0.91 & 75 & & 62 \\
& $0.93^{\mathrm{b}}$ & 75 & & 63 \\
\hline 1M Ni(II) + 0.2M Co(II) & 0.95 & & & \\
& 0.80 & 49 & & \\
& 0.83 & 50 & & \\
& 0.85 & 51 & & \\
\hline
\end{tabular}

\footnotetext{
a Total charge deposited at the indicated potential: $5 \mathrm{C} \mathrm{cm}^{-2}$

${ }^{\mathrm{b}}$ This samples were also prepared with a total charge of $3 \mathrm{C} \mathrm{cm}^{-2}$ and the Ni content was similar to that obtained with $5 \mathrm{C} \mathrm{cm}^{-2}$
} 
Click here to download high resolution image
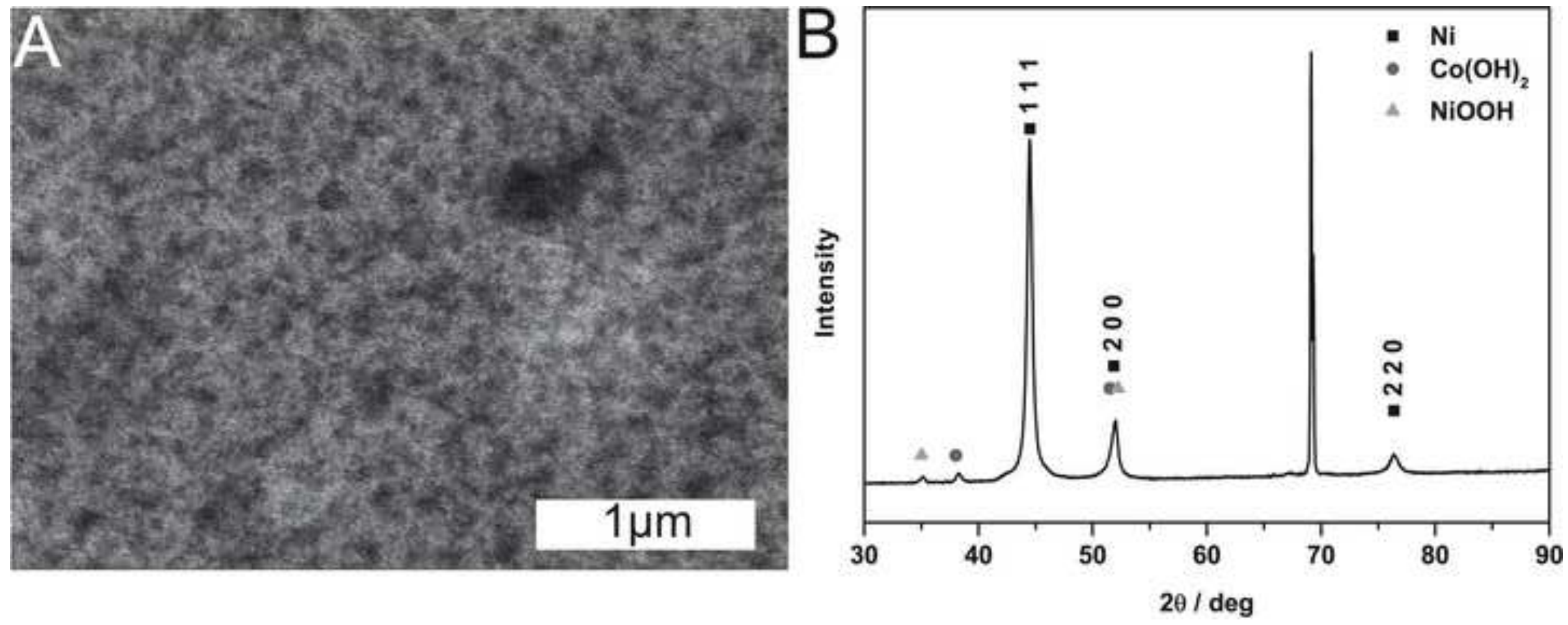

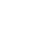


Figure 4
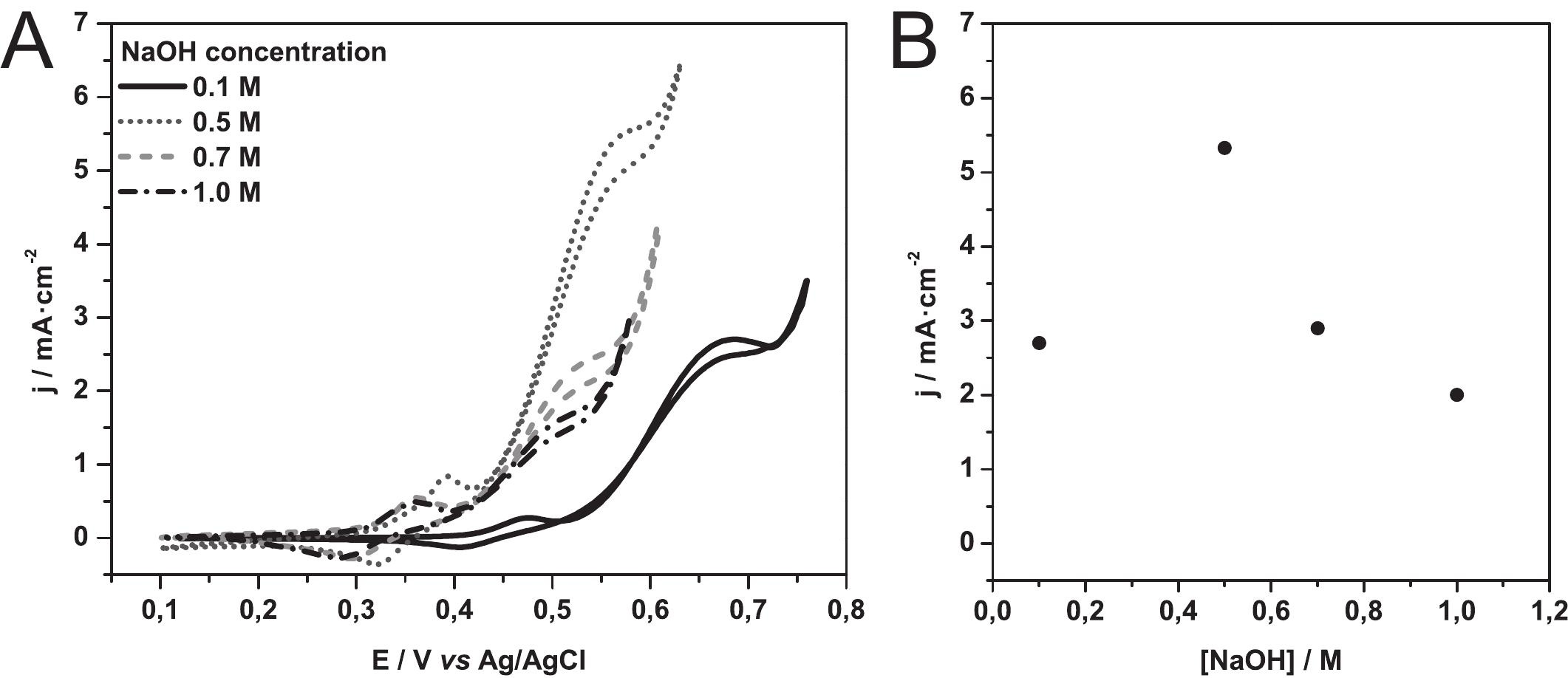


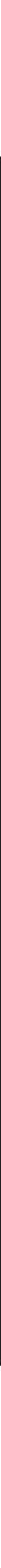

Figure 5

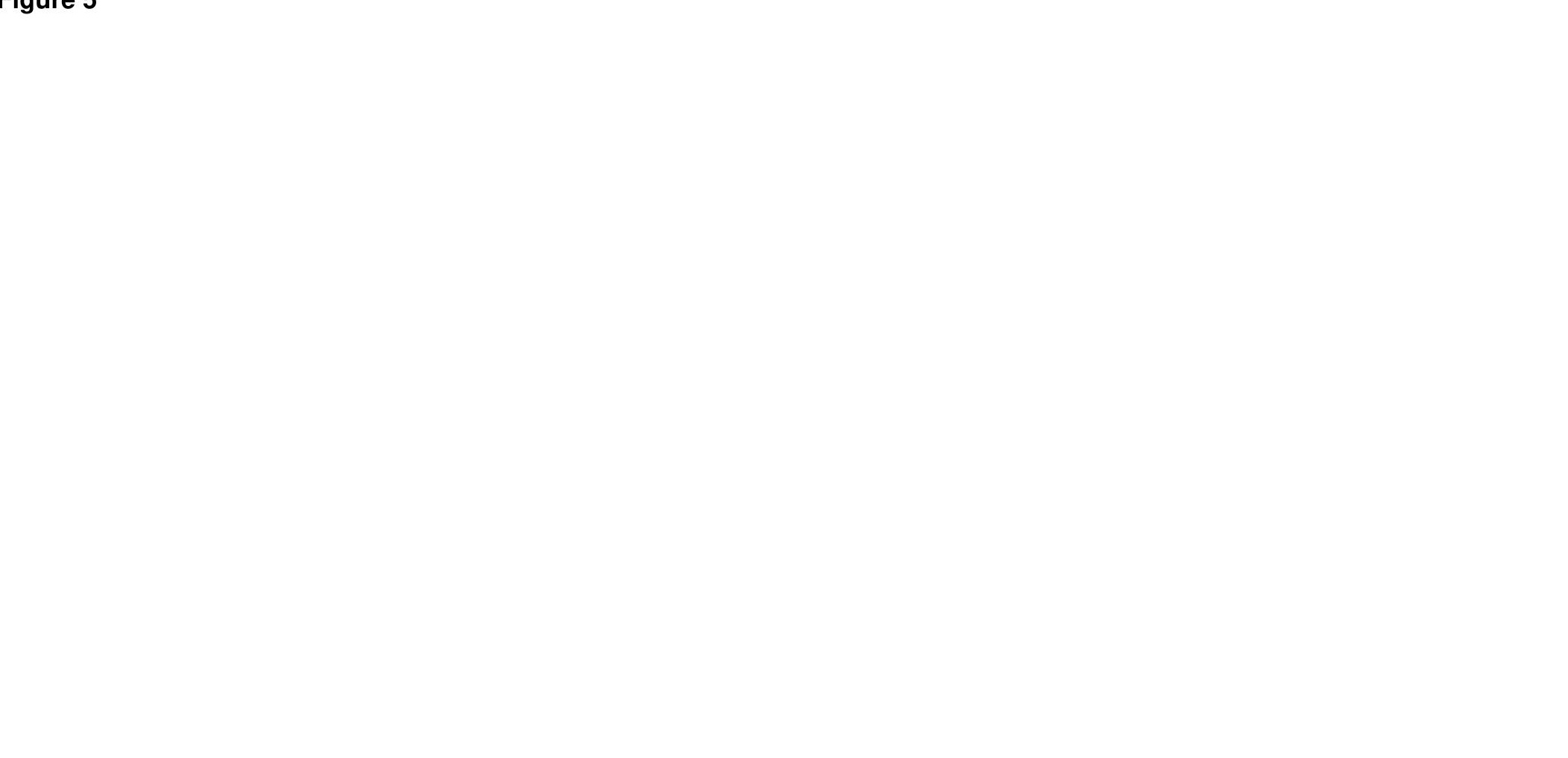


Figure 6



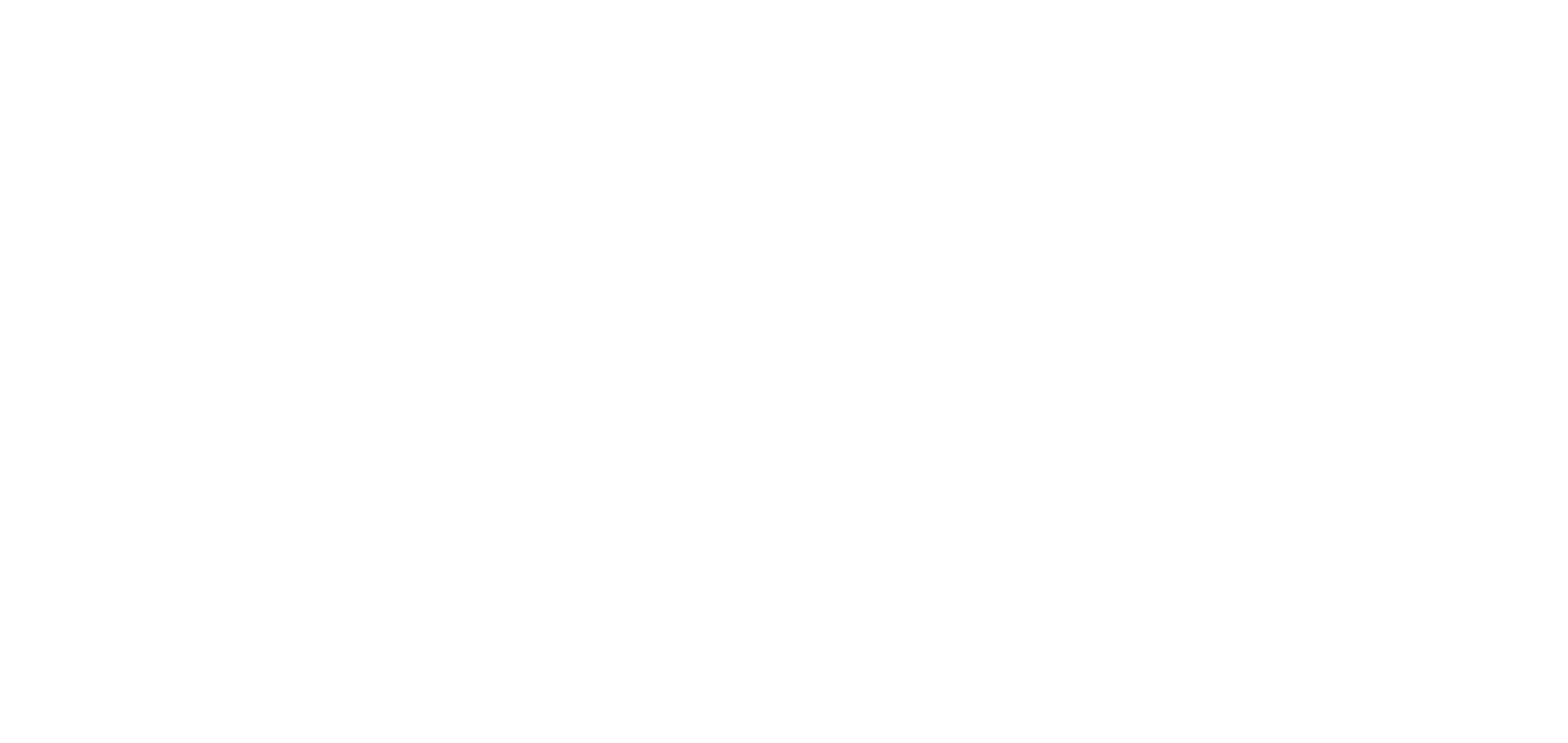


Figure 7
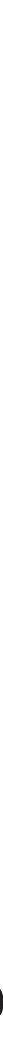


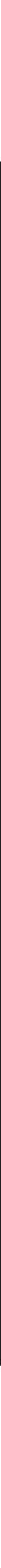

Figure 8

$\mathrm{E} / \mathrm{V}$ vs $\mathrm{Ag} / \mathrm{AgCl}$

Figure
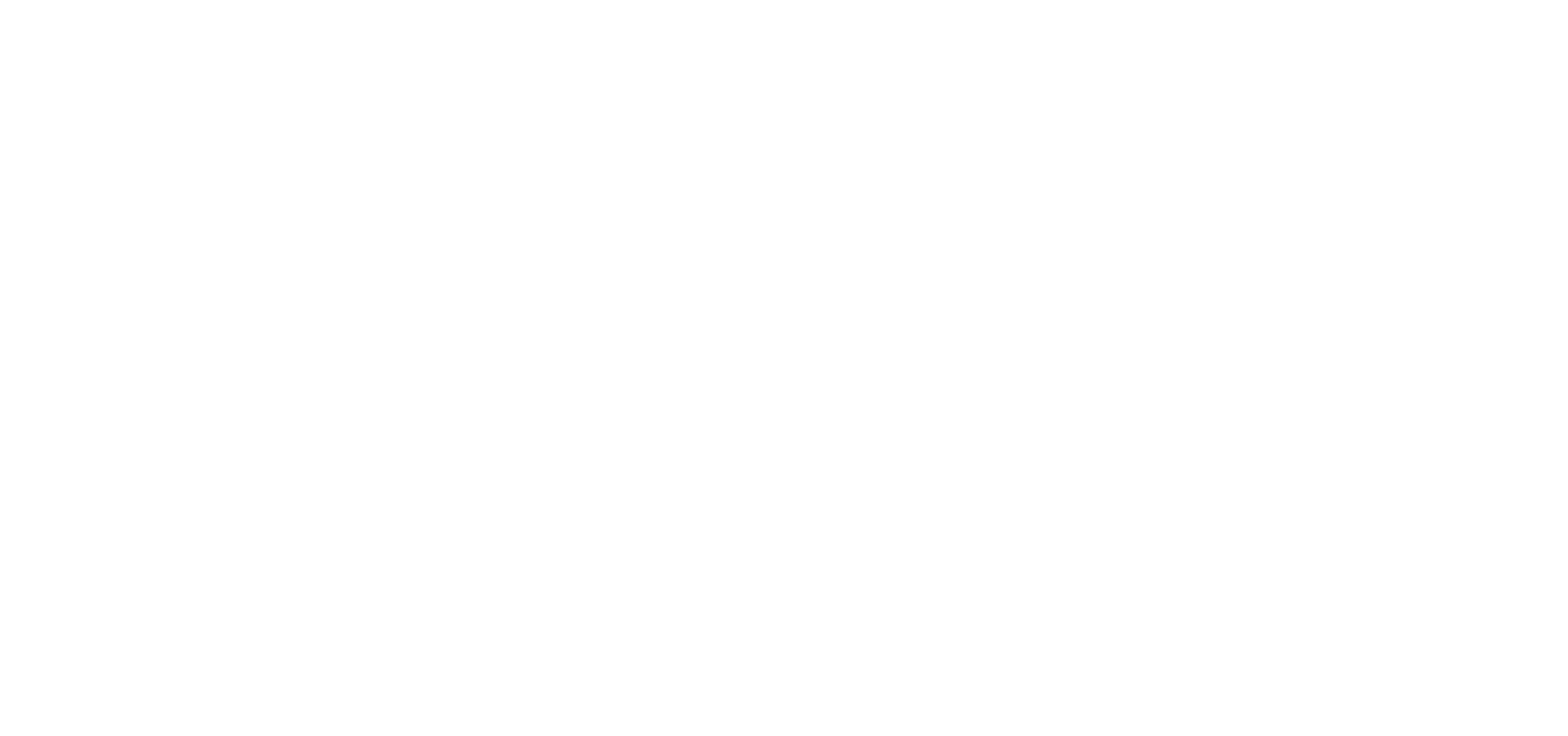

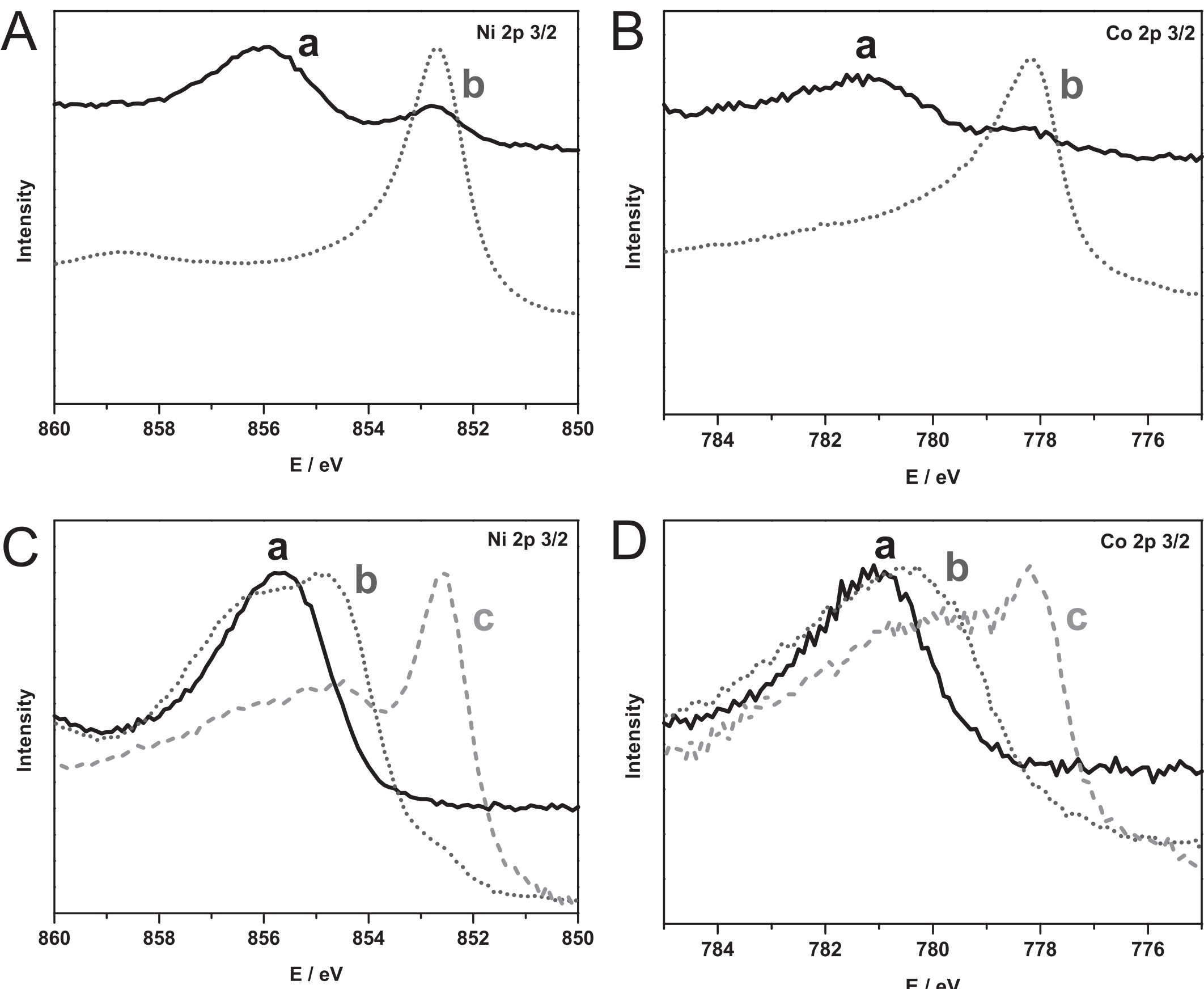

$\mathrm{E} / \mathrm{eV}$ 